\title{
ÍNDÍCES DE CONFORTO TÉRMICO E CONCENTRAÇÃO DE GASES EM GALPÕES AVÍCOLAS NO SEMIÁRIDO PARAIBANO
}

\author{
DERMEVAL A. FURTADO ${ }^{1}$, HERLUCIO P. ROCHA ${ }^{2}$, JOSÉ W. B. NASCIMENTO ${ }^{3}$, \\ JOSÉ H. V. SILVA ${ }^{4}$
}

\begin{abstract}
RESUMO: Esta pesquisa teve o objetivo de determinar os índices de conforto térmico e a concentração de gases no interior de galpões avícolas e suas influencias sobre o desempenho de frangos de corte comercias, em condições de verão, na região semiárida paraibana. Utilizaram-se dois aviários, um coberto com telha de cerâmica e outro coberto com telha de fibrocimento. Observou-se que não houve diferença significativa $(\mathrm{p}>0,05)$ entre a temperatura ambiente (TA), umidade relativa do ar (UR), temperatura da água de bebida (Tágua) e da cama entre os galpões, sendo que os valores médios de TA (das $8 \mathrm{~h}$ às $17 \mathrm{~h}$ ) e UR (das 10h às 16h) podem ser considerados fora do limite da zona de termoneutralidade recomendada para frangos de corte, como também a Tágua, no período diurno, ficou acima dos limites recomendados, que é de $24{ }^{\circ} \mathrm{C}$. Nenhum dos aviários apresentou concentrações de gases que oferecesse insalubridade para as aves e para os trabalhadores. Apesar de a Tágua e de os índices de conforto térmico, nos horários mais quentes do dia, estarem elevados, os índices produtivos ficaram dentro do estabelecido pela indústria avícola brasileira.
\end{abstract}

PALAVRAS-CHAVE: condições climáticas, produtividade, qualidade do ar.

\section{INDICES OF THERMAL COMFORT AND GASES CONCENTRATION IN BROILERS HOUSES IN THE SEMIARID REGION, BRAZIL}

\begin{abstract}
The aim of this research is to determine the thermal comfort index, the concentration of gases inside the poultry houses and their influence on the performance of commercial broiler chickens, located in the Paraiba's semiarid region, in summer conditions. It was used two poultry houses, one of them covered with a ceramic roof and the other covered with fibrous cement roof. There was no significant difference $(\mathrm{p}>0.05)$ between ambient temperature (AT), relative humidity (RH) and temperature of the drinking water (Twater) and the chicken litter between the warehouses, but the values average of AT (from 08:00 a.m. to 5:00 p.m.) and RH (from10:00 a.m. to 4:00 p.m.) can be considered outside the boundary of the comfort zone recommended for chicken broilers, but also the Twater was above the recommended limits, during the day, which is $24^{\circ} \mathrm{C}$. None of the chicken broilers showed concentrations of gases that offer an unhealthy ambient to the birds and to the workers. Although the Twater and the index of thermal comfort are elevate during the hottest days, the production indices were within the established for the Brazilian poultry industry.
\end{abstract}

KEYWORDS: climatic conditions, productivity, air quality

\section{INTRODUÇÃO}

A avaliação de índices de conforto térmico e da qualidade do ar na produção animal vem sendo referenciada como ponto de interesse em estudos de sistema de controle ambiental (BUENO \& ROSSI, 2006; MENEGALI et al., 2009), focando tanto a saúde dos animais que vivem em total confinamento, como dos trabalhadores que permanecem de 4 a 8 horas por dia nesse ambiente de

\footnotetext{
${ }^{1}$ Zootecnista, Professor Associado, UAEA/UFCG, Campina Grande - PB, dermeval@ deag.ufcg.edu.br

${ }^{2}$ Zootecnista, Mestre em Engenharia Agrícola, hprocha@yahoo.com.br

${ }^{3}$ Engenheiro Agrícola, Professor Associado, UAEA/UFCG, Campina Grande - PB, wallace@ deag.ufcg.edu.br

${ }^{4}$ Zootecnista, Professor Associado, CFT/UFPB, Bananeiras - PB, jvilar@cft.ufpb.br

Recebido pelo Conselho Editorial em: 29-7-2009

Aprovado pelo Conselho Editorial em: 29-9-2010
} 
trabalho (NÄÄS et al., 2007), como também o bem-estar animal (MOURA et al., 2010).

As aves, como animais homeotérmicos, mantêm sua temperatura corporal por meio de mecanismos fisiológicos e comportamentais. Entretanto, considerando que as aves têm temperatura corporal elevada, que de acordo com TAO \& XIN (2003), em condições de termoneutralidade, estão entre 41,2 a 42,2 ${ }^{\circ} \mathrm{C}$, podendo variar em função da temperatura ambiente, alimentação e manejo. Além destas características, as aves não possuem glândulas sudoríparas, têm o corpo coberto de penas (material isolante) e, na produção industrial, são criadas em alta densidade (BUENO \& ROSSI, 2006; NÄÄS et al., 2007; MENEGALI et al., 2009).

Deve-se ter cuidado com o conforto térmico das aves em regiões de clima quente, como é o caso da região semiárida paraibana, onde se registram altas temperaturas no interior dos aviários (SILVA et al., 2005; SOUZA et al., 2005; FURTADO et al., 2006), devendo-se aprimorar o projeto de abrigos e equacionar os manejos para superar os efeitos prejudiciais provenientes de alguns fatores ambientais críticos, propiciando aos animais ambiente confortável. Segundo BARNWELL \& ROSSI (2003), a temperatura ideal no interior dos aviários deve ser de $21,1^{\circ} \mathrm{C}$, umidade relativa do ar com média de $50 \%$ e a velocidade do vento entre 2,29 e $2,41 \mathrm{~m} \mathrm{~s}^{-1}$. Entretanto, NICHOLSON et al. (2004) recomendam que a temperatura para frangos na fase inicial esteja entre 32 a $35{ }^{\circ} \mathrm{C}$, havendo um decréscimo a cada dois dias de $1,0{ }^{\circ} \mathrm{C}$, e que, a partir da terceira semana, deve ficar entre 20 e $24{ }^{\circ} \mathrm{C}$.

Segundo FURTADO et al. (2005), a maioria dos aviários no Estado da Paraíba apresenta cobertura de telha cerâmica (55,8\% do total pesquisado), mas ainda existem muitos aviários com cobertura de telha de cimento-amianto $(39,5 \%)$, e a grande maioria dos galpões não tem sistema de resfriamento evaporativo. Devido ao elevado custo do gás, os avicultores estão utilizando cada vez mais a lenha como combustível para o aquecimento dos animais na fase inicial (ROSÁRIO et al., 2004) e, neste sentido, deve haver maiores cuidados com a qualidade do ar em virtude, principalmente, da emissão do dióxido de carbono $\left(\mathrm{CO}_{2}\right)$, monóxido de carbono $(\mathrm{CO})$ e amônia $\left(\mathrm{NH}_{3}\right)$.

Dentre outros fatores preocupantes nas instalações, encontra-se a presença dos poluentes aéreos, mais precisamente a concentração de gases em seu interior, os quais, se em grandes quantidades, alteram as características ideais do ar, favorecendo o aumento da suscetibilidade a doenças respiratórias e/ou prejuízos no processo produtivo (MIRAGLIOTA et al., 2002; BUENO \& ROSSI, 2006; NÄÄS et al., 2007; MENEGALI et al., 2009). O monitoramento da qualidade do ar em galpões de frangos de corte ocorre não somente em consequência do bem-estar animal, mas também devido à questão de saúde pública, pois a concentração de poeira e de gases, produzidos em galpões de confinamento, quando acima do tolerável, pode afetar tanto a saúde animal quanto a saúde humana (MOURA et al., 2010). Os limites permissíveis dos gases $\mathrm{NH}_{3}, \mathrm{CO}_{2}$ e $\mathrm{CO}$, segundo WATHES et al. (1998), em instalações com criação de animais em confinamento são: 20; 3.000 e 10 ppm, respectivamente. No caso de seres humanos, com uma exposição média de 8 horas diárias, os limites são de 25; 5.000, 50; 10; 3 e 10 ppm, para $\mathrm{NH}_{3}, \mathrm{CO}_{2}, \mathrm{CO}, \mathrm{H}_{2} \mathrm{~S}$, óxido nitroso $\left(\mathrm{NH}_{2}\right)$ e poeira, respectivamente.

A amônia, gás incolor, mais leve que o ar e solúvel em água, é produzida durante a degradação biológica do esterco, juntamente com o metano $\left(\mathrm{CH}_{4}\right)$ o ácido sulfídrico e o gás carbônico, sendo frequentemente encontrada em altas concentrações nos aviários, sendo que, no Brasil, não existem limites legais para a exposição de aves à amônia (OWADA et al., 2007). Segundo estes autores, uma concentração média de amônia de 0-10 caracteriza o ambiente como muito bom, de 11 a 15 ppm bom, de 16 a 20 ppm médio, de 21 a 30 ruim e de 31 a 40 como ambiente insalubre.

A HFAC - Humane Farm Animal Care (2006), cita que devem existir limites para a exposição de frangos aos gases, sendo que a concentração de $\mathrm{NH}_{3}$ deve ficar abaixo de 10 ppm e não exceder a 25 ppm, CO inferior a 10 ppm e não exceder a 50 ppm e $\mathrm{CO}_{2}$ inferior a 3.000 ppm e não exceder a 5.000 ppm. Citando a questão da insalubridade, a NR 15 - Norma Regulamentadora $\mathrm{n}^{\mathrm{o}} 15$ (1996), 
descreve como limite de tolerância 20 ppm de $\mathrm{NH}_{3}$, 29 ppm de $\mathrm{CO}$ e 3.900 ppm de $\mathrm{CO}_{2}$, com exposição de 8 horas diárias.

Objetivou-se, com este trabalho, analisar a concentração de gases, a temperatura do ar, a umidade relativa do ar, a temperatura da água e da cama de frango, a umidade da cama e os índices produtivos das aves: ganho de peso total, ganho de peso diário, conversão alimentar, taxa de mortalidade e idade de abate, em galpões de criação de frangos de corte.

\section{MATERIAL E MÉTODOS}

O experimento foi realizado em galpões de criação comercial de frangos de corte na Granja Natal - PB, localizada no município de Puxinanã - PB, inserida na região semiárida paraibana. De acordo com a classificação climática de Köeppen, o clima da região é AWi, caracterizado como clima tropical (megatérmico), com média anual de precipitação em torno de $802,7 \mathrm{~mm}$, com latitude de $07^{\circ} 09^{\prime} 0,25^{\prime \prime}$ sul e longitude de 3556'42,68” oeste e altitude de $657 \mathrm{~m}$.

O experimento ocorreu no período de janeiro a março, período seco na região semiárida paraibana, sendo que, neste período, a temperatura média do ar foi de $25,8{ }^{\circ} \mathrm{C}$, umidade relativa média de $72 \%$ e pluviosidade média de $35 \mathrm{~mm}$. Utilizou-se um total de 22.000 aves, das quais 11.500 no galpão GC (galpão com telha de cerâmica) e 10.500 no GA (galpão com telha de fibrocimento), da linhagem Cobb avian 48, constituídos de machos e fêmeas, com idade de um dia no início do experimento e 42 dias no seu final.

Os galpões estavam orientados no sentido leste-oeste e o galpão GC era construído em alvenaria, com comprimento de $125 \mathrm{~m}$, largura 12,5 m, pé-direito de 3,0 m, constituindo uma área de $1.562,59 \mathrm{~m}^{2}$, o piso interno e o passeio eram de solo-cimento; cobertura de telhas de cerâmica e beiral de 1,50 m de comprimento, além de comedouros automáticos e bebedouros automáticos do tipo nipple. O galpão GA era construído em alvenaria, com comprimento de $100 \mathrm{~m}$, largura de $10,0 \mathrm{~m}$, altura do pé-direito de $3,0 \mathrm{~m}$, constituindo uma área $1.000^{2}$, piso interno de solo-cimento e o passeio de solo argiloso; cobertura de telha ondulada de fibrocimento com seis $\mathrm{mm}$ de espessura, apoiado da mesma estrutura do galpão GC, além de comedouros automáticos e bebedouros pendulares.

O sistema de ventilação mecanizado dos galpões era constituído de 18 e 12 ventiladores axiais, para o galpão GC e GA, respectivamente, com diâmetro de $0,90 \mathrm{~m}$ e vazão nominal de $300 \mathrm{~m}^{3} \mathrm{~min}^{-1}$, posicionados transversalmente na lateral norte e sul do galpão, acionados quando a temperatura do ar ficava acima de $27^{\circ} \mathrm{C}$, permanecendo as cortinas abertas durante o manejo.

O manejo no interior das duas instalações era o mesmo. As aves receberam formulação de ração idêntica, de acordo com a sua idade; a cama de casca de arroz e bagaço de cana foi revolvida periodicamente pelos tratadores, no período noturno; o sistema de aquecimento à lenha funcionou durante os primeiros 15 dias, com as cortinas fechadas à noite, sendo que à medida que os animais foram desenvolvendo-se estas foram abertas durante o dia, e a partir da terceira semana, permaneceram levantadas.

As variáveis ambientais temperatura do ar (TA) e umidade relativa do ar (UR) foram coletadas das $8 \mathrm{~h}$ às $17 \mathrm{~h}$, a cada hora, através de um termômetro digital (LM-8000 Lutron), com o sensor posicionado a $0,40 \mathrm{~m}$ do solo, em três pontos do aviário (início, meio e fim), sendo feita a média desses dados em cada galpão (Figura 1). O monitoramento da temperatura da água foi efetuado a cada hora, em bebedouros localizados em diferentes posições, nos dois galpões, utilizando-se de um termômetro infravermelho marca Raytec (Figura 2). O mesmo equipamento foi utilizado para coletar a temperatura superficial da cama em ambos os galpões, a uma distância de $0,50 \mathrm{~m}, 1,0 \mathrm{~m}$ e $2,0 \mathrm{~m}$, da pessoa que estava coletando (fixa), para não estressar as aves, em diferentes posições, fazendo-se a média desses dados.

A umidade da cama foi calculada de acordo com a metodologia descrita por SILVA \& QUEIROZ (2002), coletada semanalmente, durante seis semanas, onde a cada semana a amostra foi 
padronizada e transportada para o laboratório para as analises. Para a avaliação da qualidade do ar ao longo do período de crescimento dos frangos, procedeu-se à mensuração da concentração dos gases oxigênio $\left(\mathrm{O}_{2}\right)$, amônia $\left(\mathrm{NH}_{3}\right)$, metano $\left(\mathrm{CH}_{4}\right)$, monóxido de carbono $(\mathrm{CO})$ e gás sulfídrico $\left(\mathrm{H}_{2} \mathrm{~S}\right)$, sendo que o $\mathrm{CO}$ foi coletado no período de aquecimento (0 ao $14^{\circ}$ dia de produção) e $\mathrm{O}_{2}$, $\mathrm{NH}_{3}, \mathrm{CH}_{4}$ e $\mathrm{H}_{2} \mathrm{~S}$ durante todo o experimento; para tanto, utilizou-se um monitor de gases portátil digital (PHD5 Biosystems ${ }^{\circledR}$ ), configurado para leitura contínua de até cinco gases no interior do galpão $\left(\mathrm{O}_{2}, \mathrm{NH}_{3}, \mathrm{CH}_{4}, \mathrm{CO}\right.$ e $\left.\mathrm{H}_{2} \mathrm{~S}\right)$ ao decorrer do experimento (Figura 3). As mensurações dos gases foram realizadas às $8 \mathrm{~h}$ e $17 \mathrm{~h}$ diariamente, a cada hora, sendo que o detector de gases estava posicionado a uma altura de $0,40 \mathrm{~m}$ do piso, em pontos aleatórios de cada galpão, fazendo-se uma média dos valores coletados.

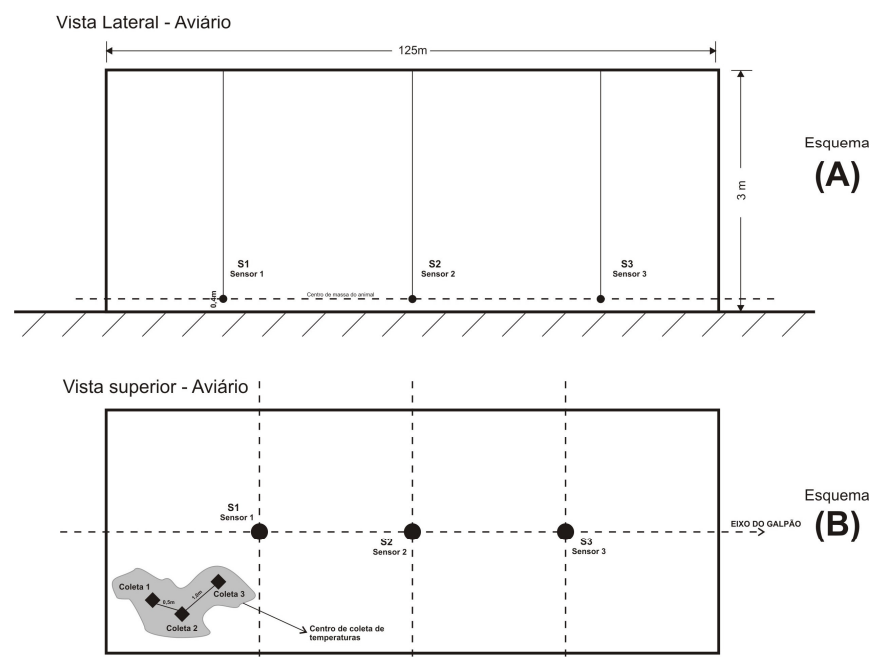

FIGURA 1. Esquema da coleta de dados. Scheme of data collection.

A avaliação do desempenho zootécnico das aves deu-se na retirada total dos lotes nos galpões, por meio dos índices de desempenho produtivo das aves, quais sejam: peso vivo (PV), que foi a relação entre o peso total do lote e o número de frangos; ganho de peso diário (GPD), diferença entre o peso vivo final e o peso vivo inicial das aves; conversão alimentar (CA), calculada pela relação entre a quantidade de ração consumida e o ganho de peso das aves; taxa de mortalidade (TM), representada pelo percentual das aves mortas durante o período experimental e idade do abate (IdAb), que foi a idade que as aves tinham no final do período experimental.

Para análise das variáveis ambientais, temperatura da cama e da água, foi realizada a análise de variância e o teste de Tukey, com o delineamento experimental inteiramente ao acaso (DIC), no esquema de parcelas subdivididas, tendo nas parcelas os galpões (GC e GA), nas subparcelas os 10 tempos de observação (das $08 \mathrm{~h}$ às $17 \mathrm{~h}$ ) com seis repetições (número de semanas do experimento médias das variáveis coletadas os sete dias da semana). As variáveis produtivas foram analisadas através da análise de variância e pelo teste de Tukey, a 5\% de probabilidade, sendo que as análises estatísticas foram realizadas utilizando-se do programa $\operatorname{ASSISTAT}^{\circledR}$ (2008).

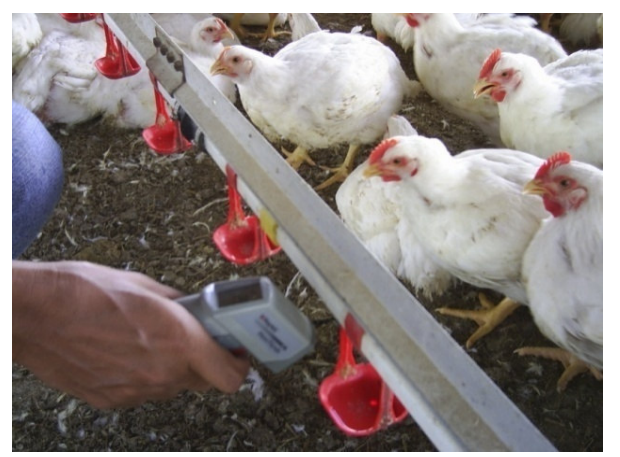

FIGURA 2. Termômetro infravermelho(Raytec®). Infrared Thermometer (Raytec®). 


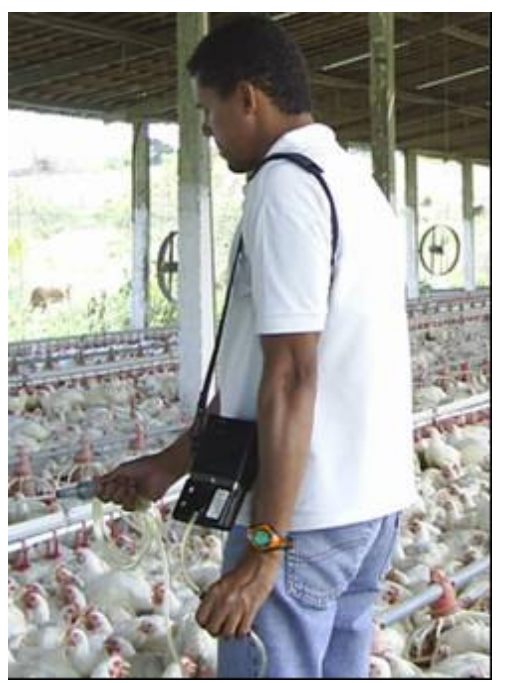

FIGURA 3. Monitor de gases portátil digital (PHD5 Biosystems®). Digital portable gas monitor (PHD5 Biosystems ®).

\section{RESULTADOS E DISCUSSÃO}

Não houve diferença significativa $(\mathrm{P}>0,05)$ entre a temperatura ambiente $(\mathrm{TA})$, umidade relativa do ar (UR), temperatura da água (Tágua) e temperatura da cama (Tcama), entre os galpões analisados. Entretanto, em relação aos valores médios da TA, UR, Tágua e Tcama dos dois galpões (Tabela 1), entre os diversos horários de observação, houve diferença significativa $(\mathrm{P}<0,05)$.

Os valores de TA, em todos os horários, podem ser considerados como acima do limite da zona de termoneutralidade recomendada para frangos de corte (NICHOLSON et al. (2004). FURTADO et al. (2006), em estudos com diferentes sistemas de acondicionamento térmico, concluíram que, na região semiárida, para os períodos diurnos, as aves estavam em situação de desconforto térmico, havendo necessidade, para os meses mais quentes do ano, do emprego de mecanismos de climatização. Situação de desconforto térmico, provocado por altas temperaturas no interior dos galpões de frangos de corte, também são relatados por SARMENTO et al. (2005); BUENO \& ROSSI (2006) e VITORASSO \& PEREIRA (2009).

TABELA 1. Valores médios da temperatura ambiente, umidade relativa do ar, temperatura da água e da cama nos galpões experimentais GC (telha cerâmica) e GA (telha fibrocimento), nos diferentes horários. Mean values of air temperature, relative humidity, water temperature and the chicken litter in experimental sheds GC (ceramic tile) and GA (fibro-cement tile), at different times.

\begin{tabular}{ccccccccc}
\hline Horas & $\begin{array}{c}\text { Temperatura Ambiente } \\
\left({ }^{\circ} \mathrm{C}\right)\end{array}$ & \multicolumn{3}{c}{ Umidade Relativa $(\%)$} & $\begin{array}{c}\text { Temperatura da Água } \\
\left({ }^{\circ} \mathrm{C}\right)\end{array}$ & $\begin{array}{c}\text { Temperatura da Cama } \\
\left({ }^{\circ} \mathrm{C}\right)\end{array}$ \\
\hline & GC & GA & GC & GA & GC & GA & GC & GA \\
\hline 8h & 28,2 & 28,6 & 58,4 & 59,3 & 27,0 & 28,2 & 29,0 & 29,6 \\
9h & 295 & 29,9 & 51,5 & 51,9 & 28,2 & 28,9 & 30,2 & 30,2 \\
$11 \mathrm{~h}$ & 30,0 & 30,8 & 47,0 & 47,7 & 29,0 & 29,3 & 30,0 & 31,8 \\
$12 \mathrm{~h}$ & 31,5 & 31,7 & 42,8 & 43,2 & 30,4 & 30,0 & 31,4 & 32,0 \\
$13 \mathrm{~h}$ & 31,7 & 32,1 & 41,0 & 41,1 & 30,6 & 31,5 & 32,0 & 32,4 \\
$14 \mathrm{~h}$ & 31,7 & 32,1 & 40,0 & 41,0 & 30,0 & 31,6 & 32,0 & 32,0 \\
$15 \mathrm{~h}$ & 31,4 & 32,1 & 41,1 & 41,1 & 301 & 30,9 & 32,0 & 31,8 \\
$16 \mathrm{~h}$ & 30,2 & 31,2 & 43,0 & 43,4 & 29,7 & 30,1 & 31,2 & 31,3 \\
$17 \mathrm{~h}$ & 28,9 & 30,2 & 47,2 & 47,9 & 29,1 & 29,1 & 30,3 & 30,9 \\
\hline
\end{tabular}

Médias seguidas da mesma letra não diferem entre si, pelo teste de Tukey, a 5\% de probabilidade. 
Nota-se, também, que nos horários das $8 \mathrm{~h}, 9 \mathrm{~h}, 16 \mathrm{~h}$ e $17 \mathrm{~h}$, os sistemas de acondicionamento obtiveram valores de UR considerados ideais na ZCT (BARNWELL \& ROSSI (2003); entretanto, em relação aos outros horários, ou seja, das $9 \mathrm{~h}$ às $15 \mathrm{~h}$, os valores encontrados no interior das instalações, nos dois sistemas, estavam fora da faixa da ZCT; portanto, a UR no interior dos galpões GC e GA apresentaram valores críticos ao longo do dia, evidenciando a necessidade da instalação de sistemas de resfriamento adiabático evaporativo nos galpões, o que poderia melhorar suas condições ambientais (TINÔCO, 2001).

Observando-se os valores médios da temperatura da água, nota-se que a temperatura média máxima foi de $31,0^{\circ} \mathrm{C}$ às $12 \mathrm{~h}$, ocorrendo um decréscimo às $17 \mathrm{~h}\left(27^{\circ} \mathrm{C}\right)$. Todos os valores estiveram acima da temperatura sugerida por MACARI \& FURLAN (2001), que citam que a temperatura da água não deve ser superior a $24,0{ }^{\circ} \mathrm{C}$, mas não ultrapassou a temperatura máxima recomendada, que é a temperatura corporal da ave, que deve estar entre 41,2 e $42,2{ }^{\circ} \mathrm{C}$ (TAO \& XIN, 2003). FURTADO et al. (2004), avaliando a influência de sistemas de acondicionamento térmico na temperatura da água, na criação de frangos de corte, na região semiárida paraibana, concluíram que esta se mostrou, no horário das 11 às 13 horas, acima da ideal.

KLOSOWSKI et al. (2004), pesquisando a temperatura da água em diferentes bebedouros, em instalações para aves de postura, também relatam que, nos vários períodos estudados, a temperatura da água foi superior à recomendada, sendo para os bebedouros "nipple" e calha, valores de 27,9 e $24,8^{\circ} \mathrm{C}$, respectivamente.

Os valores médios da temperatura da cama variaram ao longo do dia, com a temperatura média máxima na parte da manhã de $32,4^{\circ} \mathrm{C}$ às $12 \mathrm{~h}$, e as mínimas de $29,3{ }^{\circ} \mathrm{C}$ e $29,4{ }^{\circ} \mathrm{C}$, às $8 \mathrm{~h}$ e $17 \mathrm{~h}$, respectivamente. BOSHOUWERSM et al. (1996) observaram que a temperatura da cama de uma criação de frangos de corte, a partir do $19^{-}$dia de idade, foi $7^{\circ} \mathrm{C}$ superior à temperatura ambiente, justificando que tal aumento pode contribuir, juntamente com o calor gerado pelas aves e aquecedores, pelo fluxo de calor entre a instalação e o ambiente externo, para um aumento na temperatura interna dos galpões e como carga adicional de calor para as aves. Os valores relatados nos horários mais frescos do dia foram inferiores aos encontrados por MIRAGLIOTA et al. (2002), que citam valores médios da temperatura da cama de $29,3{ }^{\circ} \mathrm{C}$; entretanto, nos horários considerados mais quentes, os valores registrados foram superiores aos relatados pelos autores acima citados.

Observou-se uma relação entre a TA com a Tágua e a Tcama no interior dos galpões, sendo constatado que à medida que a TA aumentava, a Tágua e a Tcama sofriam o mesmo processo, demonstrando uma correlação entre a temperatura do ambiente e a temperatura da água e da cama, com o $\mathrm{R}^{2}$ atingindo valores de 96 e 97 , respectivamente.

Os valores da umidade da cama em função das semanas para os diferentes sistemas de acondicionamento estão apresentados na Tabela 2 , em que se observa diferença estatística $(\mathrm{P}<0,05)$ entre os galpões e durante as seis semanas do período experimental, onde a umidade da cama teve um aumento nos valores no GC no $21^{\circ}$ dia e no GA no $14^{\circ}$ e $21^{\circ}$ dia, sendo que, no início da terceira semana de vida das aves, a umidade da cama atingiu valores de 30,9 e 38,2\%, nos sistemas GC e GA, respectivamente, apresentando estabilidade nos valores após o $28^{\circ}$ dia. Este valor mais elevado no galpão GA pode ser devido à maior densidade de alojamento de aves, como também reflexo de suas menores dimensões.

Este aumento no valor da umidade da cama no galpão GA $(38,2 \%)$, no $14^{\circ}$ e $21^{\circ}$ dia, foi decorrente de uma diarreia crônica que as aves apresentaram, alterando assim a composição da cama, e o decréscimo a partir do $28^{\circ}$ dia deu-se devido ao controle da enfermidade nos galpões e ao manejo da cama, com seu revolvimento constante. Os valores da umidade da cama, nas duas semanas inicias e finais do período experimental, foram semelhantes às relatadas por FURTADO et al. (2006), também em trabalhos com frangos de corte na região semiárida paraibana. 
TABELA 2. Valores da umidade da cama para os diferentes galpões. Values of chicken litter moisture to the different sheds.

\begin{tabular}{ccccccc}
\hline Galpões & \multicolumn{5}{c}{ Dias Após o Início do Experimento } \\
\hline & 7 & 14 & 21 & 28 & 35 & 42 \\
GC & $20,5 \mathrm{Af}$ & $23,1 \mathrm{Ae}$ & $30,9 \mathrm{Ab}$ & $28,1 \mathrm{Ac}$ & $27,9 \mathrm{Acd}$ & $32,5 \mathrm{Aa}$ \\
GA & $21,2 \mathrm{Ae}$ & $30,4 \mathrm{Bbc}$ & $38,2 \mathrm{Ba}$ & $31,5 \mathrm{Ab}$ & $30,6 \mathrm{Abc}$ & $28,7 \mathrm{Ad}$ \\
\hline
\end{tabular}

Médias seguidas da mesma letra maiúscula na coluna e minúscula na linha não diferem entre si, pelo teste de Tukey, a $5 \%$ de probabilidade.

Não houve diferença significativa $(\mathrm{p}>0,05)$ entre os galpões na concentração dos gases $\mathrm{O}_{2}$, $\mathrm{CH}_{4}, \mathrm{CO}, \mathrm{NH}_{3}$ e $\mathrm{H}_{2} \mathrm{~S}$, e na Tabela 3, observam-se as concentrações médias desses gases nos dois galpões analisados. As concentrações de $\mathrm{O}_{2}$ observadas foram de 20,9\%, situando-se dentro de situações de salubridade, não oferecendo situação de risco nos galpões, sendo que o limite mínimo recomendado de $\mathrm{O}_{2}$ é de 19,5\% (NÄ̈̈S et al., 2007). Estes valores também podem ser justificados pela pequena densidade de alojamento dos galpões, como também estes eram abertos e construídos em locais com boa altitude $(657 \mathrm{~m})$, portanto sujeitos a boa ventilação.

TABELA 3. Concentração média dos dois sistemas de oxigênio $\left(\mathrm{O}_{2}\right)$, amônia $\left(\mathrm{NH}_{3}\right)$, monóxido de carbono $(\mathrm{CO})$, metano $\left(\mathrm{CH}_{4}\right)$ e gás sulfídrico $\left(\mathrm{H}_{2} \mathrm{~S}\right)$. Average concentration of the two oxygen systems (O2), ammonia (NH3), carbon monoxide (CO), methane (CH4) and hydrogen sulfide (H2S).

\begin{tabular}{lccccc}
\hline \multirow{2}{*}{ Gases } & \multicolumn{5}{c}{ Horários / Concentração } \\
\cline { 2 - 6 } & $8-9 \mathrm{~h}$ & $10-11 \mathrm{~h}$ & $12-13 \mathrm{~h}$ & $14-15 \mathrm{~h}$ & $16-17 \mathrm{~h}$ \\
\hline Oxigênio $-\mathrm{O}_{2}(\%)$ & 30,0 & 20,9 & 20,9 & 20,9 & 20,9 \\
Amônia - $\mathrm{NH}_{3}(\mathrm{ppm})$ & 4,5 & 4,5 & 4,5 & 4,5 & 4,5 \\
Monóxido de Carbono - CO $(\mathrm{ppm})$ & 12,2 & 12,2 & 0,0 & 0,0 & 0,0 \\
Metano - $\mathrm{CH}_{4}(\mathrm{ppm})$ & $<0,1$ & $<0,1$ & $<0,1$ & $<0,1$ & $<0,1$ \\
Gás Sulfídrico - $\mathrm{H}_{2} \mathrm{~S}(\mathrm{ppm})$ & $<1,0$ & $<1,0$ & $<1,0$ & $<1,0$ & $<1,0$ \\
\hline
\end{tabular}

As médias de $\mathrm{NH}_{3}$ nos dois galpões criação foram de 4,5 ppm e estiveram dentro dos limites aceitáveis para instalações avícolas e para os trabalhadores, podendo, segundo a NR 15 (1996) e OWADA et al. (2007), caracterizar o ambiente como muito bom. Estes valores estão de acordo com os relatados por NÃ̃̃ S et al. (2007) e VITORASSO \& PEREIRA (2009), que, em trabalhos em diferentes galpões, também relatam valores de amônia abaixo de 20 ppm. Observa-se, na Tabela 4, que as médias de concentração de $\mathrm{CO}$ encontradas entre os galpões foram inferiores às recomendadas pela NR (1990) e HFA (2006), mesmo com a utilização de aquecedores a lenha, que podem provocar fumaça no interior das instalações. Tomando por base as recomendações da HFAC (2006), observa-se que o nível de CO foi superior ao recomendado (10 ppm), mas não excedendo os $50 \mathrm{ppm}$.

Estes valores foram superiores aos relatados por MENEGALI et al. (2009), que em trabalhos com frangos de corte, em condições de inverno, na região Sul do Brasil, encontraram valores de CO variando de 2,65 a 8,79 ppm. Porém foram inferiores aos citados por NÄ̈̈S et al. (2007), que relatam, na fase de aquecimento dos pintainhos, valores em período frios de $30 \mathrm{ppm}$ (sistema de ventilação tipo túnel) e 18 ppm (com ventilação convencional).

VIGODERIS et al. (2010) e CORDEIRO et al. (2010), estudando a influência da ventilação mínima no conforto térmico, clima da região, qualidade do ar e desempenho zootécnico em galpões avícolas, observaram que os tratamentos com ventilação mínima resultam em menores valores de concentração de gases. As concentrações médias de $\mathrm{CH}_{4}$ e $\mathrm{H}_{2} \mathrm{~S}$ foram inferiores aos limites sugeridos pela CIGR (1994) e a HFAC (2006) para aves e trabalhadores e aos limites sugeridos pela ACGIH (2001) para o trabalhador, ficando, portanto, o ambiente dentro da salubridade para a concentração de gases e dos índices bioclimáticos. Esta baixa concentração de gases pode estar 
associada às condições tipológicas dos galpões, já que estes eram construções totalmente abertas (laterais e oitões), com boa ventilação, inclusive quando necessário, com auxílio da ventilação mecânica.

Os valores médios das variáveis produtivas peso vivo (PV), ganho de peso diário (GPD), conversão alimentar (CA) e taxa de mortalidade (TM), dos dois sistemas analisados, estão apresentados na Tabela 4 , em que se observa que não houve diferença significativa ( $>>0,05)$, pelo teste de Tukey, destes índices entre os galpões e, mesmo com os galpões apresentando índices de conforto térmico (TA e UR), nos horários considerados mais quentes, acima do recomendado, como também a temperatura da água elevada, de maneira geral, pode-se observar certa uniformidade nos valores encontrados para os índices produtivos, os quais estiveram dentro das faixas tidas como ideais pela indústria avícola do País.

TABELA 4. Valores médios das variáveis produtivas PV (kg), GPD (g), CA e TM (\%) dos dois sistemas de produção avaliados. Mean values of the production variables PV (kg), GPD (g) CA and TM (\%) of the two production systems evaluated.

\begin{tabular}{ccccc}
\hline Sistemas & PV $(\mathrm{Kg})$ & GPD $(\mathrm{g})$ & CA & TM (\%) \\
\hline GC & 2,39 & 56,91 & 1,92 & 4,1 \\
GA & 2,32 & 55,42 & 1,91 & 4,0 \\
\hline
\end{tabular}

Analisando os valores de PV e fazendo uma adaptação para 42 dias dos valores médios encontrados por FURTADO el al. (2006), que em pesquisas com diferentes sistemas de condicionamento do ambiente, citam valores de 2,32 kg de PV, observa-se que estes foram bastante próximos ao da presente pesquisa, como também os citados por SILVA et al. (2005), analisando diferentes tipos de bebedouros e por SARMENTO et al. (2005), em galpões tradicionais (2,28 kg) e galpões semiclimatizados $(2,58 \mathrm{~kg})$, sendo esses trabalhos realizados na região Nordeste do Brasil.

Os valores de GPD, para GC (56,9 g) e GA (55,4 g), estão dentro das médias obtidas no Brasil por diversos autores, como SARMENTO et al. (2005), SILVA et al. (2005), FURTADO et al. (2006), na região Nordeste, e inferiores aos citados por CARVALHO et al. (2009), na região Sudeste. A CA teve valor médio de 1,915, que pode ser considerado ótimo, semelhante aos valores relatados por SILVA et al. (2005), FURTADO et al. (2006) e BUENO \& ROSSI (2006). A TM foi em média de $4,05 \%$, dentro dos padrões exigidos pela indústria avícola de corte, mas superior à relatada por MIRAGLIOTA et al. (2002) e BUENO \& ROSSI (2006), em trabalhos no Sudeste do Brasil e por FURTADO et al. (2006) em trabalho no Estado da Paraíba, que foi em média de 2,79\%.

\section{CONCLUSÕES}

As variáveis ambientais e a temperatura da água, apesar de estarem elevados no interior dos galpões no período diurno, não influenciaram nos índices produtivos, os quais apresentaram resultados satisfatórios para a produção de frangos de corte da região do semiárido paraibano, mostrando a viabilidade da atividade na região em estudo.

As concentrações de amônia, monóxido de carbono, gás sulfídrico, metano e oxigênio, mensurados nos dois galpões, apresentaram limites adequados à saúde das aves e dos trabalhadores.

\section{REFERÊNCIAS}

ACGIH. AMERICAN CONFERENCE GOVERNMENT INDUSTRIAL HYGIENISTS. Threshold limit values for chemical substances and biological exposure indices. Cincinnati, 2001. 185 p.

ASSISTAT. Programa de análises estatísticas. Versão Beta 7.2. Campina Grande: Departamento de Engenharia Agrícola, CTRN, UFCG, 2008.

BARNWELL, R.; ROSSI, A. Maximização da performance em períodos quentes. Avicultura Industrial, São Paulo, v.11, p.72-80, 2003. 
BOSHOUWERS, F.M.G.; DAVELAAR, F.G.; LANDMAN, W.J.M.; NICAISE, E.; VAN De BOS, J. Vertical temperature profiles at bird level in broiler houses. British Poultry Science, London, v.37, n.1, p.55-62, 1996.

BUENO, L.; ROSSI, L.A. Comparação entre tecnologias de climatização para criação de frangos quanto à energia, ambiência e produtividade. Revista Brasileira de Engenharia Agrícola e Ambiental, Campina Grande, v.10, n.2, p.497-504, 2006.

CARVALHO, J.C.C.; BERTECHINI, A.G.; FASSANI, E.J.; RODRIGUES, P.B.; PEREIRA, R.A.N. Desempenho e características de carcaça de frangos de corte alimentados com dietas à base de milho e farelo de soja suplementadas com complexos enzimáticos. Revista Brasileira de Zootecnia, Viçosa-MG, v.38, n.2, p.292-298, 2009.

CIGR. COMMISSION INTERNATIONALE DU GÉNIE RURAL. Aerial environment in animal housing: concentrations in and emissions from farm buildings. Dublin, 1994. $116 \mathrm{p}$.

CORDEIRO, M.B.; TINÔCO, I.F.F.; SILVA, J.N.; VIGODERIS, R.B.; PINTO, F.A.C.; CECON, P.R. Conforto térmico e desempenho de pintos de corte submetidos a diferentes sistemas de aquecimento no período de inverno. Revista Brasileira de Zootecnia, v.39, n.1, p.217-224, 2010.

FURTADO, D.A.; DANTAS, R.T.; NASCIMENTO, J.W.B.; SANTOS, J.T.; COSTA, F.G.P. Efeitos de diferentes sistemas de acondicionamento ambiente sobre o desempenho produtivo de frangos de corte. Revista Brasileira de Engenharia Agrícola e Ambiental, Campina Grande, v.10, n.2, p.484489, 2006.

FURTADO, D.A.; NASCIMENTO, J.W.B.; AZEVEDO, M.A.; LEAL, A.F. Influência da pintura das telhas na temperatura da água em galpões de frangos de corte. Revista Brasileira de Ciência Avícola, Campinas, Supl., 6, p.165, 2004.

FURTADO, D.A.; TINÔCO, I.F.F.; NASCIMENTO, J.W.B.; LEAL, A.F.; AZEVEDO, M.A. Caracterização das instalações avícolas na Messoregião do Agreste Paraibano. Engenharia Agrícola, Jaboticabal, v.25, n.3, p.831-840, 2005.

HFAC. HUMANE FARM ANIMAL CARE. Padrões do HFAC para a produção de frangos de corte. Disponível em: <http://www.certifiedhumane.com/pdfs/Std04.Broilers.3A_po..pdf $>$. Acesso em: 7 jul. 2005.

KLOSOWSKI, E.S.; CAMPOS, A.T.; GASPARINO, E.; AMARAL, D.F. Temperatura da água em bebedouros utilizados em instalações para aves de postura. Engenharia Agrícola, Jaboticabal, v.24, n.3, p.493-500, 2004.

MACARI, M.; FURLAN, R.L. Ambiência na produção de aves em clima tropical. In: SILVA, I.J.O. Ambiência na produção de aves em clima tropical. Piracicaba: SBEA, 2001. p.31-87.

MENEGALI, I.; TINÔCO, I.F.F.; BAÊTA, F.C.; CECON, P.C.; GUIMARÃES, M.C.C.;

CORDEIRO, M.B. Ambiente térmico e concentração de gases em instalações para frangos de corte no período de aquecimento. Revista Brasileira de Engenharia Agrícola e Ambiental, Campina Grande, v.13, p.984-990, 2009. Suplemento

MIRAGLIOTA, M.Y.; NÄÄS, I.A.; BARACHO, M.S.; ARADAS, M.E.C. Qualidade do ar de dois sistemas de produção de frangos de corte com ventilação e densidade diferenciadas - estudo de caso. Engenharia Agrícola, Jaboticabal, v.22, n.1, p.1-10, 2002.

MOURA, D.J.; BUENO, L.G.F.; LIMA, K.A.O.; CARVALHO, T.M.R.; MAIA, A.P.A. Strategies and facilities in order to improve animal welfare, Revista Brasileira de Zootecnia, Viçosa-MG, v.39, p.311-316, 2010. Suplemento Especial.

NÄÄS, I.A.; MIRAGLIOTTA, M.Y.; BARACHO, M.S.; MOURA, D.J. Ambiência aérea em alojamento de frangos de corte: poeira e gases. Engenharia Agrícola, Jaboticabal, v.27, n.2, p.326334, 2007. 
NICHOLSON, F.A.; CHAMBERS, B.J.; WALKER, A.W. Ammonia emissions from broiler litter and laying hen manure management systems. Biosystems Engineering, v.89, n.2, p.175-185, 2004.

NR-15 BRASIL. Ministério do Trabalho. Portaria n. 3.214 de 8 de junho de 1978: Normas regulamentadoras relativas à segurança e medicina do trabalho. In: Manual de Legislação de Atlas de Segurança e Medicina do Trabalho. 33.ed. São Paulo: Atlas, 1996. 523 p.

OWADA, N.A.; NÄÄS, I.A.; MOURA, D.J.; BARACHO, M.S. Estimativa de bem estar de frango de corte em função da concentração de amônia e grau de luminosidade no galpão de produção. Engenharia Agrícola, Jaboticabal, v.27, n.3, p.611-618, 2007.

ROSÁRIO, M.F.; SILVA, M.A.; COELHO, A.A.D.; SAVINO, V.J.M. Síndrome ascítica em frangos de corte: uma revisão sobre a fisiologia, avaliação e perspectivas. Ciência Rural, Santa Maria, v.34, n.6, p.1.987-1.996, 2004.

SARMENTO, L.G.V.; DANTAS, R.T.D.; FURTADO, D.A.; NASCIMENTO, J.W.B.; SILVA, J.H.V. Efeito da pintura externa do telhado sobre o ambiente climático e o desempenho de frangos de corte. Revista Agropecuária Técnica, Areia, v.26, n.2, p.152-159, 2005.

SILVA, D.J.; QUEIROZ, A.C. Análise de alimentos: métodos químicos e biológicos. 3.ed. Viçosa: UFV, 2002. $165 \mathrm{p}$.

SILVA, J.H.V.; FILHO, J.J.; SILVA, E.L.; RIBEIRO, M.R.G.; FURTADO, D.A. Efeito do bebedouro e da densidade no desempenho de frangos alojados em alta temperatura. Revista Brasileira de Engenharia Agrícola e Ambiental, Campina Grande, v.9, n.4, p.636-641, 2005.

SOUZA, B.B.; BERTECHINI, A.G.; TEIXEIRA, A.S.; LIMA, J.A.F.; CONTE, A.J. Efeito do nível energético e da suplementação com cloretos de potássio e de amônia sobre as respostas fisiológicas e o desempenho de frangos de corte no verão. Revista Ciência e Agrotecnologia, Lavras, v.29, n.1, p.185-192, 2005.

TAO, X.; XIN, H. Acute synergistic effects of air temperature, humidity, and velocity on homeostasis of market-size broilers. Transactions of the ASAE, St. Joseph, v.46, n.2, p.491-497, 2003.

TINÔCO, I.F.F. Avicultura industrial: novos conceitos de materiais. Concepções e técnicas construtivas disponíveis para galpões brasileiros. Revista Brasileira de Ciência Avícola, Campinas, v.3, n.1, p. 1-26, 2001.

VIGODERIS, R.B.; CORDEIRO, M.B.; TINÔCO, I.F.F.; MENEGALI, I.; SOUZA JÚNIOR, J.P.; HOLANDA, M.C.R. Avaliação do uso de ventilação mínima em galpões avícolas e de sua influência no desempenho de aves de corte no período de inverno. Revista Brasileira de Zootecnia, v.39, n.6, p.1.381-1.386, 2010.

VITORASSO, G.; PEREIRA, D.F. Análise comparativa do ambiente de aviários de postura com diferentes sistemas de acondicionamento. Revista Brasileira de Engenharia Agrícola e Ambiental, Campina Grande, v.13, n.6, p.788-794, 2009.

WATHES, C.M.; HOLDEN, M.R.; SNEATH, R.W.; WHITE, R.P.; PHILLIPS, V.R. Concentrations and emissions rates of aerial ammonia, nitrous oxide, methane, carbon dioxide, dust and endotoxin in UK broiler and layer houses. British Poultry Science, London, v.38, n.1, p.14-28, 1998. 